\title{
Three-dimensional natural convection of CNT-water nanofluid confined in an inclined enclosure with Ahmed body
}

\author{
Abdullah A.A.A. Al-RASHED*, K. KALIDASAN**, Lioua KOLSI***,****, \\ Mohamed Naceur BORJINI**** and P. Rajesh KANNA***** \\ *Dept. of Automotive and Marine Engineering Technology, College of Technological Studies, The Public Authority for Applied Education \\ and Training, Kuwait \\ ${ }^{* *}$ Department of Civil Engineering, Arulmigu Palaniandavar Polytechnic College, Palani, Tamilnadu - 624 601, India. \\ ${ }^{* * *}$ College of Engineering, Mechanical Engineering Department, Haïl University, Haïl City , Saudi Arabia \\ E-mail: lioua_enim@yahoo.fr
}

****Unité de Métrologie et des Systèmes Énergétiques, École Nationale d'Ingénieurs, Monastir, University of Monastir, Tunisia

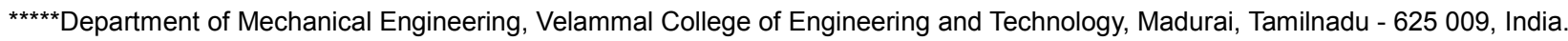

Received: 19 November 2016; Revised: 25 December 2016; Accepted: 3 January 2017

\begin{abstract}
A finite volume based three dimensional numerical studies on the heat transfer due to natural convection inside the inclined cubical cavity filled with CNT-water nanofluid is solved by vorticity-vector potential formalism. The enclosure contains an Ahmed body at its middle with differentially heated vertical walls. The other walls are adiabatic. The effect due to Rayleigh number $\left(10^{3} \leq \mathrm{Ra} \leq 10^{5}\right)$, volumetric fraction $(0 \leq \varphi \leq 0.05)$ of CNT particles, angle of incidence of enclosure $\left(0^{\circ} \leq \gamma \leq 180^{\circ}\right)$ and thermal conductivity ratio $\left(0.01 \leq R_{c} \leq 100\right)$ are analyzed. The results of fluid flow with single phase model are elucidated with Particle trajectories, Velocity vectors, Iso-surfaces of temperature and Nusselt number. CNT-particles enhanced the heat transfer in all the considered cases. Maximum average Nusselt number is reported when the angle of inclination is $30^{\circ}$ and $150^{\circ}$. The variation in thermal conductivity ratio has a least effect on convection.
\end{abstract}

Key words : Natural convection, Inclined cavity, Nanofluid, Ahmed body, Nusselt number

\author{
Nomenclature \\ Be Bejan number \\ $C_{p} \quad$ Specific heat at constant pressure $(\mathrm{J} / \mathrm{kg} . \mathrm{K})$ \\ $g \quad$ Gravitational acceleration $\left(\mathrm{m} / \mathrm{s}^{2}\right)$ \\ $k \quad$ Thermal conductivity (W/m.K) \\ $l \quad$ Enclosure width \\ $n \quad$ unit vector normal to the wall. \\ $N_{s} \quad$ Dimensionless local generated entropy \\ $\mathrm{Nu} \quad$ Local Nusselt number \\ Pr Prandtl number \\ $\mathrm{Ra} \quad$ Rayleigh number \\ $R_{c} \quad$ Thermal conductivity ratio $\left(\mathrm{k}_{\mathrm{s}} / \mathrm{k}_{\mathrm{f}}\right)$ \\ $S^{\prime}{ }_{\text {gen }} \quad$ Generated entropy $(\mathrm{kJ} / \mathrm{kg} . \mathrm{K})$ \\ $t \quad$ Dimensionless time $\left(t^{\prime} \cdot \alpha / l^{2}\right)$ \\ $T$ Dimensionless temperature $\left[\left(T^{\prime}-T_{c}{ }_{c}\right) /\left(T^{\prime}{ }_{h}-T^{\prime}{ }_{c}\right)\right]$ \\ $T^{\prime}{ }_{c} \quad$ Cold temperature (K) \\ $T^{\prime}{ }_{h} \quad$ Hot temperature $(\mathrm{K})$ \\ $T_{o} \quad$ Bulk temperature $\left[T_{o}=\left(T^{\prime}{ }_{c}+T^{\prime}{ }_{h}\right) / 2\right]$ \\ $\vec{V} \quad$ Dimensionless velocity vector $\left(\vec{V}^{\prime} l / \alpha\right)$ \\ $x, y, z$ Dimensionless coordinates $\left(x^{\prime} / l, y^{\prime} / l, z^{\prime} / l\right)$ \\ Greek symbols
}




\section{Introduction}

Natural convection inside the square cavity is used in many industrial applications like crystal growth, cooling of electronic chips, solar collectors, nuclear reactor and energy efficient buildings. Initially study on the cavity was performed without any protrusions or blocks inside it (De Vahl, 1989;Corcione et al., 2015). Later the study is extended on the enclosure with different forms of obstacle inside it like square (Mahmoodi \& Sebdani, 2012), circular (Sarkar et al., 2012) and baffle (Kalidasan et al., 2014).

The study on angle of inclination of cavity on natural convection is essential since the earth's surface is rarely aligned with geo-potential lines (Ghasemi \& Aminossadati, 2009). Huelsz \& Rechtman (2013) conducted the research on inclined enclosure with air and found that the steady state flow is symmetric with respect to a reflection in the inclination angle. Abu-Nada \& Oztop (2009) investigated the angle of inclination on a cavity with nanofluid and indicated a low heat transfer when the angle of inclination is $90^{\circ}$. Singh and Singh (2016) numerically analyzed the free convection and radiation in a tilted cavity and showed that the heat transfer increases first and then decreases with decreasing cavity tilt angle for all Rayleigh number and emissivity. Ghasemi \& Aminossadati (2009) indicated that the inclination angle has a significant impact on the flow, temperature fields and the heat transfer performance at high Rayleigh numbers on a cavity with nanofluid during natural convection. Esfandiary et al. (2016) performed two phase model study on an inclined cavity with $\mathrm{Al}_{2} \mathrm{O}_{3}$-water nanofluid and concluded that the highest Nusselt number is obtained at the inclination of $30^{\circ}$.

The invention of nanofluid attracts more researches towards the natural convection (Khanafer et al., 2003; Ho et al., 2008; Eslamian et al., 2015). CNT nanoparticles with higher thermal conductivity and lower density enhanced the natural convection. Ding et al. (2006) experimentally observed that higher thermal conductivity, particle re-arrangement, shear induced thermal conduction, reduction of thermal boundary layer thickness and very high aspect ratio of MWCNTs are responsible for enhanced convection. Glory et al. (2008) experimentally measured the thermal and electrical conductivities of MWCNT-water nanofluid and found that long tubes reduce the number of contacts among them and favour phonon transmission which ultimately increase the thermal conductivity. Halelfadl et al. (2013) experimentally analyzed the viscosity of MWCNT-water nanofluid and indicated that the relative viscosity of nanouid at high shear rate is independent of temperature. Rahman et al. (2015) investigation of unsteady natural convection and statistical analysis on a cavity with non - isothermal heating indicates that the addition of CNT fraction ratio becomes insignificant at small Rayleigh numbers but it affects both the flow and heat transfer for higher Rayleigh numbers. Heris et al. (2014), presented a comparative experimental study on the natural convection heat transfer of different metal oxide nanopowders suspended in turbine oil inside an inclined cubic cavity, it was found that for an inclination of $90^{\circ}$, and a weight fraction of $0.2 \%$, the use of $\mathrm{TiO}$ particles gives the maximum of heat transfer, while for weight fraction of $0.8 \%$, this maximum number is associated to the $\mathrm{CuO}$ nano-powders. Rashidi et al. (2014) investigated the effect of the heterogeneous heating on the natural convection of the $\mathrm{Al}_{2} \mathrm{O}_{3}$ nanofluid inside a square cavity. The results reveal that for high Rayleigh numbers, the heat transfer is minimal where the heat flux in the vicinity of adiabatic wall is smallest, while the heat flux near the cold wall is biggest. Ho et al. (2014) carried out a numerical and experimental study on nanofluid natural convection heat transfer considering Ludwig-Soret effect and sedimentation. The comparisons between experimental data and numerical results unfold that when Ludwig-Soret effect, Brownian motion and sedimentation of nanoparticles are considered in the numerical model, the predicted Nusselt number is very close to experimental data. Mahian et al. (2016) studied numerically and experimentally the natural convection of silica nanofluid in square and triangular enclosures. The main conclusion was that the use of the experimental data of thermophysical properties may give different trends of heat transfer coefficient.

Three-dimensional simulations yield accurate results over two-dimensional analysis. Shen et al. (2016) conducted experimental and three dimensional numerical analysis on square, $45^{\circ}$ inclined square and triangular cavities on natural convection. They found that the critical cavity tilt angle (from steadiness to unsteadiness) increases with decreasing aperture ratio or increasing heat flux. Kolsi et al. (2016a) comprehensively studied the cubical cavity filled with nanofluid and triangular inserts and concluded that three dimensional solution brings more understanding work for the study. Wang et al. (2010) numerically studied the inclined porous cubical cavity and indicate that when the angle of inclination of the cavity is $75^{\circ}$ to $90^{\circ}$, the flow patterns inside are unstable and become complicated. Kolsi et al. (2016b) numerically investigated the cubical cavity with $\mathrm{Al}_{2} \mathrm{O}_{3}$ nanofluid and diagonal blocks and revealed that the average Nusselt number rose with the increase in $R a$ and volumetric fraction of solid particles and declined with the increase in block size. Sheremet et al. (2015) numerically studied the porous cubical cavity with Buongiorno's model 
and found that the average Nusselt number at the hot surface is an increasing function of the Rayleigh number and Brownian motion parameter, and a decreasing function of the Lewis number, buoyancy - ratio and thermophoresis parameters.

Ahmed body is rectangular in shape with a skewed surface on the top-right corner. Ahmed body is a popular geometry in automobile industries. The slant on the back side of the body modified the flow physics inside the cavity (Thacker et al., 2013). Banga et al. (2015) numerically studied the Ahmed body and found that the velocity vectors in the wake region depend on the slant angle. But the heat transfer due to natural convection on a cavity with Ahmed body is not studied so far. Hence the nucleus of the present result is to investigate the heat transfer due to natural convection on an inclined cubical cavity having Ahmed body at its middle and filled with CNT- water nanofluid. CNT particles are preferred over other solid particles due to lower density and higher thermal conductivity. To get accurate results even at higher concentration of CNT-particles, Xue model (Xue, 2005) of thermal conductivity is preferred over other conventional models as indicated by (Kalidasan \& Kanna, 2016).

\section{Problem Statement}

The schematic representation of the problem is presented in fig. 1. Ahmed body with skew back is placed at the middle of the cubical cavity as shown in fig. 1. The vertical walls along x-direction are differentially heated while all other walls including top and bottom walls are considered as adiabatic. The cavity is filled with high thermally conductive CNT-water nanofluid having a $\operatorname{Pr}$ value as 6.2. The thermo-physical properties of the base fluid (water) and solid phase (CNT) are presented in Table 1. The percentage of CNT particles is varied between 0 to $5 \%$. The thermal conductivity ratio is varied between 0.01 and 100. Nanofluid is assumed to be a Newtonian fluid. The flow is three-dimensional, laminar, incompressible and unsteady. Boussinesq approximation has been applied to assume constant density of the nanofluid. The vorticity - vector potential formalism $(\vec{\psi}-\vec{\omega})$ eliminates the pressure and simplify the numerical simulations on a cubical cavity. The vector potential and the vorticity are defined respectively by the following two relations:

$$
\vec{\omega}^{\prime}=\vec{\nabla} \times \vec{V}^{\prime} \quad \text { and } \quad \vec{V}^{\prime}=\vec{\nabla} \times \vec{\psi}^{\prime}
$$

The non-dimensional governing equations are:

$$
\begin{gathered}
-\vec{\omega}=\nabla^{2} \vec{\psi} \\
\frac{\partial \vec{\omega}}{\partial t}+(\vec{V} . \nabla) \vec{\omega}-(\vec{\omega} . \nabla) \vec{V}=\frac{v_{n f}}{v_{f}} \operatorname{Pr} . \Delta \vec{\omega}+\frac{\beta_{n f}}{\beta_{f}} \operatorname{Ra} \operatorname{Pr}\left[\frac{\partial T}{\partial z} \cos (\gamma) ;-\frac{\partial T}{\partial z} \sin (\gamma) ;-\frac{\partial T}{\partial x} \cos (\gamma)+\frac{\partial T}{\partial y} \sin (\gamma)\right] \\
\frac{\partial T}{\partial t}+\vec{V} . \nabla T=\frac{\alpha_{n f}}{\alpha_{f}} \nabla^{2} T \quad \text { in fluid zone } \\
\frac{\partial T}{\partial t}=\frac{\alpha_{s}}{\alpha_{n f}} \nabla^{2} T \text { in solid zone }
\end{gathered}
$$

The time $\left(t^{\prime}\right)$, velocity $\left(\vec{V}^{\prime}\right)$, vector potential $\left(\vec{\psi}^{\prime}\right)$ and vorticity $\left(\vec{\omega}^{\prime}\right)$, are put respectively in their dimensional forms by $l^{2} / \alpha, \alpha / l, \alpha$ and $l^{2} / \alpha$.

The non-dimensional temperature is defined by : $T=\left(T^{\prime}-T_{c}{ }^{\prime}\right) /\left(T_{h}{ }^{\prime}-T_{c}{ }^{\prime}\right)$

The non-dimensional numbers are: $\operatorname{Pr}=\frac{v}{\alpha} \quad$ and $\quad R a=\frac{g \cdot \beta \cdot \Delta T \cdot l^{3}}{v \cdot \alpha}$

Ahmed body (solid portion of the domain) conductivity ks, is assumed constant.

At the solid-fluid interface the continuity of temperature and heat flux is expressed as:

$\left(\frac{\partial T}{\partial n}\right)_{n f}=R_{c}\left(\frac{\partial T}{\partial n}\right)_{s}$ With $R_{c}=k_{s} / k_{n f}$

The effective density of the nanofluid is assumed to be constant and is given by (Kahveci, 2010) as:

$$
\rho_{n f}=(1-\varphi) \rho_{f}+\varphi \rho_{s}
$$

The effective dynamic viscosity of the nanofluid is given by Brinkman model as: 


$$
\mu_{n f}=\frac{\mu_{f}}{(1-\varphi)^{2.5}}
$$

The heat capacitance of the nanofluid is expressed as:

$$
\left(\rho C_{p}\right)_{n f}=(1-\varphi)\left(\rho C_{p}\right)_{f}+\varphi\left(\rho C_{p}\right)_{s}
$$

The thermal expansion coefficient of the nanofluid is:

$$
(\rho \beta)_{n f}=(1-\varphi)(\rho \beta)_{f}+\varphi(\rho \beta)_{s}
$$

The effective thermal conductivity of the CNT-water nanofluid is approximated by (Xue, 2005) as:

$$
\frac{k_{n f}}{k_{f}}=\frac{1-\varphi+2 \varphi \frac{k_{s}}{k_{s}-k_{f}} \ln \left(\frac{k_{s}+k_{f}}{2 k_{f}}\right)}{1-\varphi+2 \varphi \frac{k_{f}}{k_{s}-k_{f}} \ln \left(\frac{k_{s}+k_{f}}{2 k_{f}}\right)}
$$

Table 1. Thermophysical properties of water and CNT nanoparticles

\begin{tabular}{l|l|l}
\hline Physical properties & Water & CNT \\
\hline$C_{p}(\mathrm{~J} / \mathrm{kg} . \mathrm{K})$ & 4179 & 650 \\
$\rho\left(\mathrm{kg} / \mathrm{m}^{3}\right)$ & 997.1 & 1350 \\
$k(\mathrm{~W} / \mathrm{m} . \mathrm{K})$ & 0.613 & 3500 \\
$\beta(1 / \mathrm{K})$ & $21.10^{-5}$ & $4.2 .10^{-5}$ \\
\hline
\end{tabular}

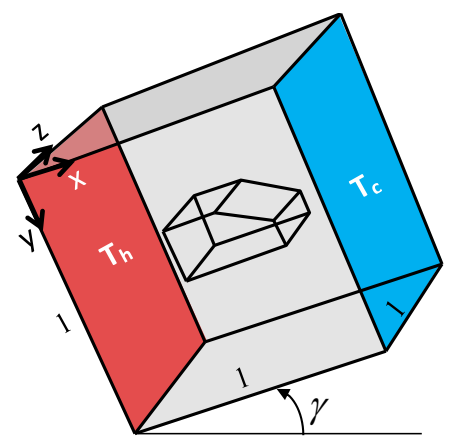

a) Iso-view of the Geometry

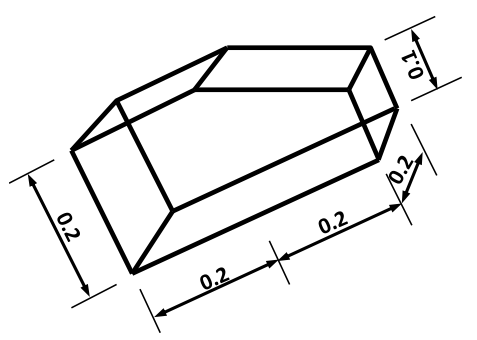

b) Iso-view of Ahmed body

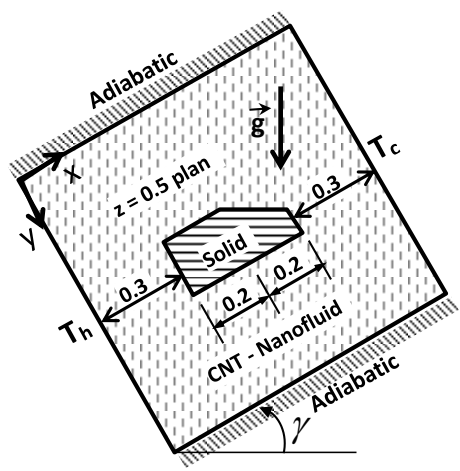

c) $2 \mathrm{D}$ view of the Geometry

Fig 1. Geometrical representation of the problem

\section{Boundary conditions}

The boundary conditions for the present problem are given as follows:

\section{Temperature:}

$T=0 \quad$ for $\quad x=1 ; T=1$ for $x=0 ; \frac{\partial T}{\partial n}=0$ on other walls (i.e., adiabatic).

\section{Vorticity :}

$\omega_{x}=0, \quad \omega_{y}=-\frac{\partial V_{z}}{\partial x}, \quad \omega_{z}=\frac{\partial V_{y}}{\partial x}$ at $x=0$ and $1 ; \quad \omega_{x}=\frac{\partial V_{z}}{\partial y}, \omega_{y}=0, \omega_{z}=-\frac{\partial V_{x}}{\partial y} \quad$ at $\quad y=0 \quad$ and $1 ; \quad \omega_{x}=-\frac{\partial V_{y}}{\partial z}$, $\omega_{y}=\frac{\partial V_{x}}{\partial z}, \omega_{z}=0$ at $z=0$ and 1

\section{Vector potential:}

$\frac{\partial \psi_{x}}{\partial x}=\psi_{y}=\psi_{z}=0 \quad$ at $\quad x=0$ and $1 ; \psi_{x}=\frac{\partial \psi_{y}}{\partial y}=\psi_{z}=0$ at $y=0$ and $1 ; \psi_{x}=\psi_{y}=\frac{\partial \psi_{z}}{\partial z}=0$ at $z=0$ and 1 


\section{Velocity :}

$V_{x}=V_{y}=V_{z}=0 \quad$ on all walls

The surface averaged instantaneous local Nusselt number $(\mathrm{Nu})$ along the wall is calculated by:

$$
N u=\left.\left(\frac{k_{n f}}{k_{f}}\right) \frac{\partial T}{\partial x}\right|_{x=0,1}
$$

Furthermore, the average Nusselt number $\left(N u_{a v}\right)$ on the isothermal wall is evaluated by:

$$
N u_{a v}=\int_{0}^{1} \int_{0}^{1} N u \cdot d y \cdot d z
$$

The mathematical model is solved using the program written in FORTRAN. The control volume finite difference method is used for discretion of the governing equations. The central-difference scheme is applied for treating convective terms while the fully implicit procedure is used for discretion of the temporal derivatives. The grids are uniform in all directions with additional nodes on the boundaries. The successive relaxation iteration scheme is used to solve the non-linear algebraic equations. The time step $\left(10^{-4}\right)$ and spatial mesh $\left(81^{3}\right)$ are used to conduct the numerical simulations. The simulation is terminated when the convergence criteria given in equation (7) is satisfied.

$$
\sum_{i}^{1,2,3} \frac{\max \left|\psi_{i}^{n}-\psi_{i}^{n-1}\right|}{\max \left|\psi_{i}^{n}\right|}+\max \left|T_{i}^{n}-T_{i}^{n-1}\right| \leq 10^{-5}
$$

\section{Grid dependency and validation}

The grid independence test has been performed on the cubical enclosure with $R a=10^{5}, \varphi=0.025, R_{c}=1$ and angle of inclination as $30^{\circ}$. The tests have been performed for the spatial meshes of $61^{3}, 71^{3}, 81^{3}$ and $91^{3}$. The average Nusselt number on the hot wall is considered as a sensitive parameter. The results of the analysis with $\mathrm{Ra}=10^{5}, \gamma=$ $30^{\circ}, R_{c}=1$ and $\varphi=2.5 \%$ is presented in the Table 2 . The incremental increase in percentage of $N u_{a v g}$ for the size $81^{3}$ to $91^{3}$ is only $0.149 \%$. Hence for computational economy and accuracy, spatial mesh size of $81^{3}$ is opted for all the simulations.

Table 2. Grid sensitivity analysis

\begin{tabular}{llll}
\hline Grid size & $\mathbf{N} \boldsymbol{u}_{\boldsymbol{a v g}}$ & Percentage increase & Incremental increase \\
\hline $\mathbf{6 0}$ & 7.4772 & - & - \\
$\mathbf{7 1}^{\mathbf{3}}$ & 7.5945 & 1.568769 & - \\
$\mathbf{8 1}$ & 7.72969 & 3.376799 & 1.780104 \\
$\mathbf{9 1}^{\mathbf{3}}$ & 7.74124 & 3.531268 & 0.149424 \\
\hline
\end{tabular}

The validation of the present code for cavity containing conductive block is carried out by comparing the present results with 2D numerical simulation of Das and Reddy, (2006), with $\operatorname{Pr}=0.71, \operatorname{Ra}=10^{6}, \gamma=-60^{\circ}$ and $R_{c}=5$. The streamlines and isotherms are compared at $\mathrm{z}=0.5$ plan and presented in fig. 2. For nanofluid filled cavity, results are compared against the work of (Jahanshahi et al., 2010) and presented in fig. 3. For 3D analysis, results are validated with those of (Wakashima \& Saitoh,2004; and Fusegi et al., 1991) and presented in the Table 3. The present results are in good agreement with the earlier published results.

\section{Results and Discussion}

A finite volume based three dimensional numerical analysis on natural convection is performed on an inclined square enclosure filled with CNT-water nanofluid. The enclosure has an Ahmed body at the middle. The enclosure is differentially heated on the vertical walls while the horizontal walls are considered as adiabatic. The thermal conductivity ratio $\left(R_{c}\right)$ is selected as a control parameter for heat transfer and Rayleigh number is used as a buoyancy enhancing parameter. The intensity of heat transfer is modified through volumetric fractions of CNT-particles and angle of incidence of the cavity.

\subsection{Flow Field}

The flow field is illustrated through particle trajectories and velocity vector diagrams. Fig. 4 represents the particle trajectories for the pure fluid at moderate Rayleigh number $\left(10^{5}\right)$ when the thermal conductivity ratio is unity. At this $R a$, 
the inertia forces are dominated by the viscous forces surrounding the solid surfaces and the particle trajectories are revolved around the walls. The particle trajectories encircle the Ahmed body. The slant on the backside of the Ahmed body attracts more movement around it than the front surface and hence particle trajectories are denser around it. Similarly, the angle of incidence has significant effect on the particle trajectories. When the angle is $30^{\circ}$ and $120^{\circ}$, the trajectories are closely packed when compared with other angle of incidences. For all angles of inclination $\left(\right.$ except $\left.90^{\circ}\right)$ the flow structure is characterized by a convergent internal flow from front and back walls to the central plan. The external flow is more intensive near of the active walls and is also convergent towards the central plan. For $\gamma=90^{\circ}$ the flow structure is more complex due to the configuration which is similar to the Rayleigh Bénard case.

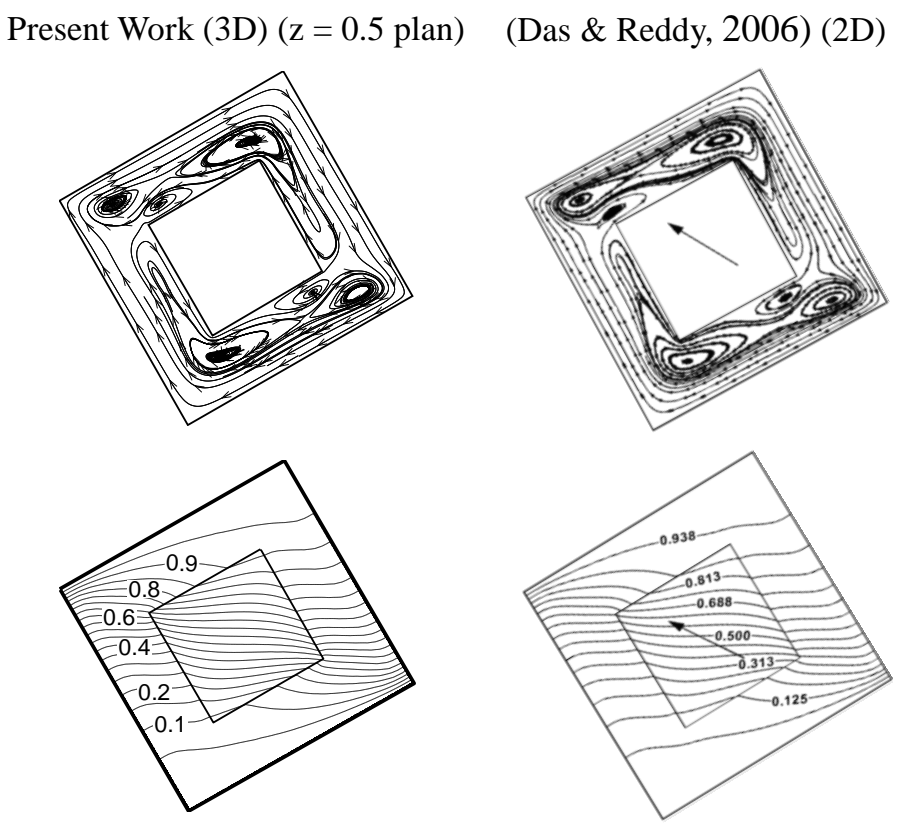

Fig. 2. Validation of the code with (Das \& Reddy, 2006); $\operatorname{Pr}=0.71, R a=10^{6}, \gamma=-60^{\circ}$ and $R_{c}=5$.

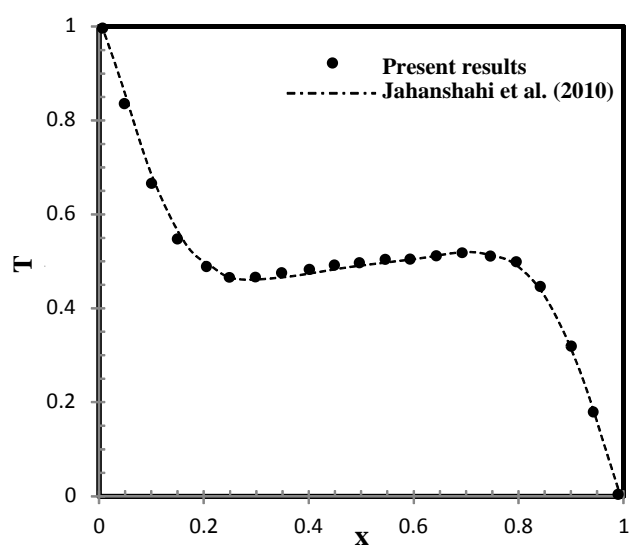

Fig. 3. Comparison of the temperature on axial midline between the present results (cubic cavity; $z=0.5$ plan) and results of Jahanshahi et al. (2010) $\left(\operatorname{Pr}=6.2, \varphi=0.1\right.$ and $\left.R a=6.2 \times 10^{4}\right)$.

When the CNT-particles are introduced, the heat transfer increases and hence intensity of flow also increased (fig. 5). At the angle of inclination of $90^{\circ}$, the trajectories are uniformly distributed throughout the enclosure.

The velocity vectors moves clockwise surrounding the Ahmed body due to the differential heating of the vertical walls. For pure water, when $\gamma$ is $0^{\circ}$ (fig.6) and $R_{c}$ is low (0.01), the inertia forces dominate the viscous forces and hence two recirculation cells are generated on the diagonal opposite corners at $z=0.5$ plan. The two recirculations are formed at the bottom-left corner and the top-right corner. Due to the increasing buoyancy, the recirculation zone near the slant of the Ahmed body is slightly bulges than the bottom eddy. When inertia forces are increased through the enhanced $R_{c}$, the sizes of the vortices gets reduced and they diminish at high $R_{c}$. When $R_{c}$ is increased the increase in viscous forces attracts the velocity vectors towards the Ahmed body and hence the contour intervals are reduced. In 
fact, when the conductivity ratio is enhanced, the inertia forces are neutralized by the viscous forces and hence the size of the recirculation zone gets reduced. When $R_{c}$ is high, the recirculation zones are completely vanished and viscous force enforces highly paced contours around the Ahmed body. When CNT particles are introduced, the strength of heat fluxes are increased and the increased buoyancy results the swelling of recirculation zones. Due to these phenomena, recirculation cells are noticed in all the range of $R_{c}$. When $R_{c}=1$, the recirculation zone extends up to the height of the Ahmed body. At $(z=0.75)$, the reduction of hydrodynamic blockage effect reduced the vectors spacing and vortices are noticed in all the values of $R_{c}$. When $(z=0.95)$, the presence of viscous forces near the wall reduce the momentum and the sizes of the vortices gets reduced. The increased buoyancy near the skew portion of the Ahmed body uplifts the right side recirculation cell. The introduction of CNT-particles enhanced the convection resulting the bulging of vortices in all the cases when compared with pure fluid.

Table 3: Comparison of present results with the three dimensional numerical results of (Wakashima \& Saitho, 2004; and Fusegi et al., 1991) for differentially heated cubic cavity with air as a fluid

\begin{tabular}{ccccccc}
\hline$R a$ & Authors & $\psi_{z}($ center $)$ & $\omega_{z}($ center $)$ & $V_{x \max }(\mathrm{y})$ & $V_{y \max }(\mathrm{x})$ & $N u_{a v}$ \\
\hline $10^{4}$ & Present work & 0.05528 & 1,1063 & $0,199(0,826)$ & $0,221(0,112)$ & 2,062 \\
\hline & (Wakashima \& Saitho, 2004) & 0.05492 & 1,1018 & $0,198(0,825)$ & $0,222(0,117)$ & 2,062 \\
\hline & (Fusegi et al., 1991) & --- & --- & $0,201(0,817)$ & $0,225(0,117)$ & 2,1 \\
\hline $10^{5}$ & Present work & 0.034 & 0,262 & $0,143(0,847)$ & $0,245(0,064)$ & 4,378 \\
\hline & (Wakashima \& Saitoh, 2004) & 0.03403 & 0,2573 & $0,147(0,85)$ & $0,246(0,068)$ & 4,366 \\
\hline & Fusegi et al., (1991) & --- & --- & $0,147(0,855)$ & $0,247(0,065)$ & 4,361 \\
\hline $10^{6}$ & Present work & 0.01972 & 0,1284 & $0,0832(0,847)$ & $0,254(0,032)$ & 8,618 \\
\hline & (Wakashima \& Saitho, 2004) & 0.01976 & 0,1366 & $0,0811(0,86)$ & $0,2583(0,032)$ & 8,6097 \\
\hline & (Fusegi et al., 1991) & --- & --- & $0,0841(0,856)$ & $0,259(0,033)$ & 8,77 \\
\hline
\end{tabular}

When $\gamma$ is $30^{\circ}$ (Fig.7), the effect of inclination reduced the momentum of flow and hence the sizes of the recirculation cells decrease and are completely vanished for pure water and velocity vectors are tends to pack densely around the Ahmed body as the conductivity ratio increases. Both eddies vanished at $(z=0.5)$ plan. When $(z=$ 0.95), the recirculation cell on the left side vanished completely and the right side cell diminishes at high conductivity ratios. Again the addition of nano particles creates recirculation zones at low $R_{c}$ due to the surge in buoyancy.

When $\gamma$ is $60^{\circ}$ (fig.8) and for pure fluid, small sized recirculation cells formed again at $(z=0.5)$ due to the inclination effect the velocity vector projections are leanly packed with increasing interval. The right side cell vanished completely at $(z=0.75)$ plan. At $(z=0.95)$ plan, both the cells merged and a single recirculation cell generates at the center. With the addition of CNT-particles, two baby vortices are noticed at $R_{c}=0.01$ and 1 when $(z=$ $0.75)$.

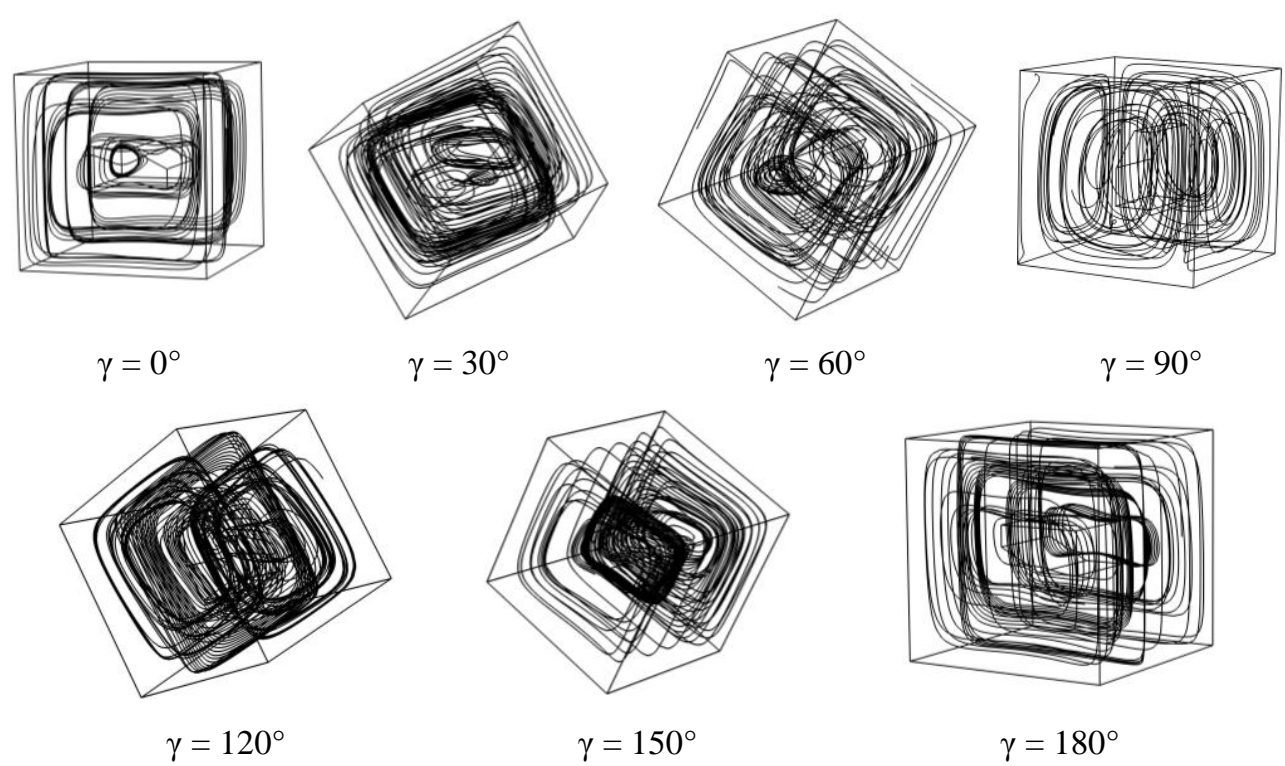

Fig.4. Some particles trajectories for $R a=10^{5} ; \varphi=0 ; R_{c}=1$ and different inclinations 
When $\gamma$ is $90^{\circ}$ (fig.9) and for pure fluid, the momentum is maximum due to the reduction of hydrodynamic blockage due to the vertical placing of Ahmed body and many recirculation cells are visible at $(z=0.5)$. For this angle the effect of inclination is more pronounced. The velocity vectors changed its direction to anticlockwise direction and many recirculation cells are reported. At $(z=0.75)$, the vortices merged at the middle and the vortex become an oval shape. At $(z=0.95)$, the strength of vortex gets reduced but it tilt slightly towards right. The addition of nano-particles bulged the vortex and the physics is same that of a pure fluid.

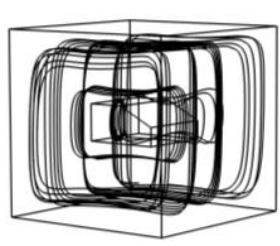

$\gamma=0^{\circ}$

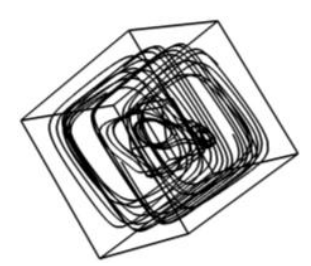

$\gamma=120^{\circ}$

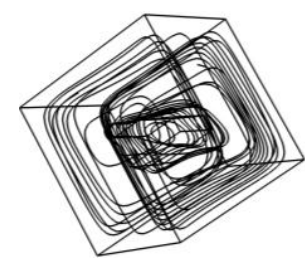

$\gamma=30^{\circ}$

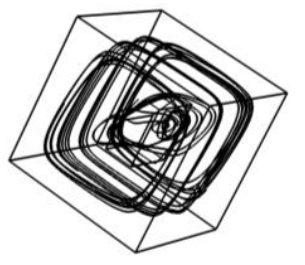

$\gamma=60^{\circ}$

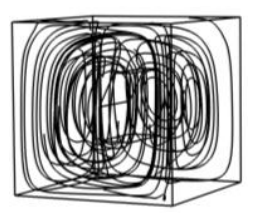

$\gamma=90^{\circ}$

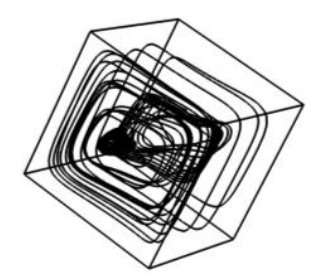

$\gamma=150^{\circ}$

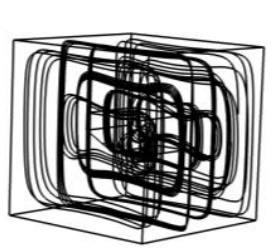

$\gamma=180^{\circ}$

Fig.5. Some particles trajectories for $R a=10^{5} ; \varphi=0.05 ; R_{c}=1$ and different inclinations

\subsection{Heat Transfer}

The iso-surfaces of temperature are presented in fig. 10 for $R a=10^{5}$ and $\varphi=0.05$ for different angles of incidence. The iso-surfaces are concentrating around the vertical walls. The iso-surfaces are closely packed when the angle of inclination is $0^{\circ}$ and $180^{\circ}$. When inclination is increased they start to collide and tend to mix near to the Ahmed body and stratification occurred at the middle of enclosure. This is due to the presence of recirculation surrounded by the body. These approaches to a crest intermingle at $90^{\circ}$. Due to the presence of adiabatic walls on the top and bottom, thermal stratifications are absent around the horizontal walls. This trend is common for both the pure fluid and nanofluid, however for nanofluid the stratification is denser.

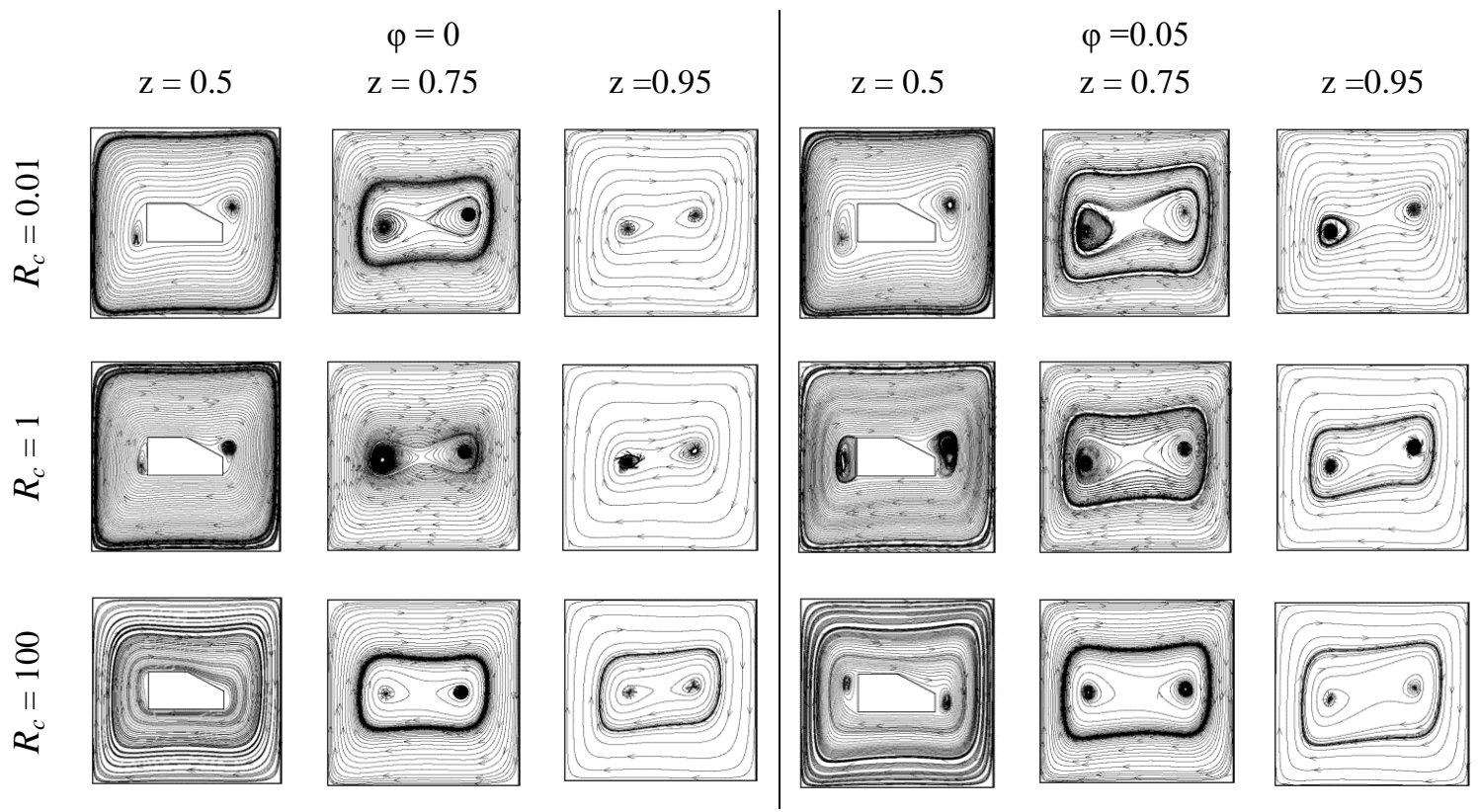

Fig.6. Velocity vector projection at different z-plans for $\gamma=0^{\circ}$ and $\mathrm{Ra}=10^{5}$ 
Fig. 11 depicts the local Nusselt number distribution on the hot wall for $R a=10^{5}$ and $R_{c}=1$. Fluid flows parallel to the hot wall and turn at the top corner and further spread in the downstream again deflected by right side wall and flows down and complete the cycle. At zero inclination the local Nusselt number distribution is parallel to x-y plane and non-linearity appears at bottom of the wall only. When inclination increases fluid becomes more stratified and local Nusselt number exhibits two-dimensionality in the wall. At $90^{\circ}$ a diagonal symmetry is observed in local $\mathrm{Nu}$. When nanoparticles are added that enhances convective heat transfer and local Nusselt number is approximately doubled. Highest heat transfer is reported when $\gamma$ is $0^{\circ}$ and $180^{\circ}$ for both the pure fluid and nanofluid.

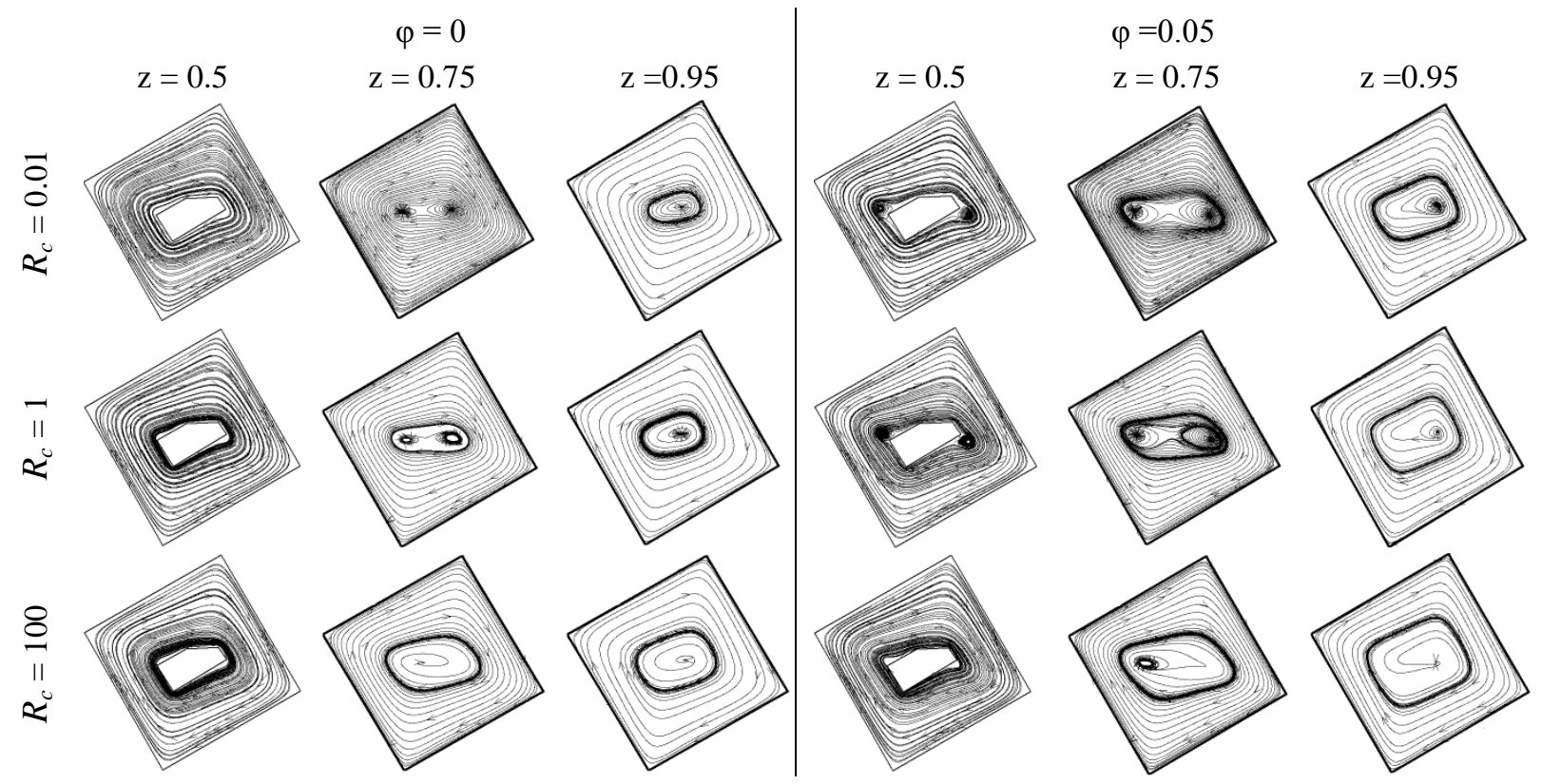

Fig.7. Velocity vector projection at different z-plans for $\gamma=30^{\circ}$ and $\mathrm{Ra}=10^{5}$

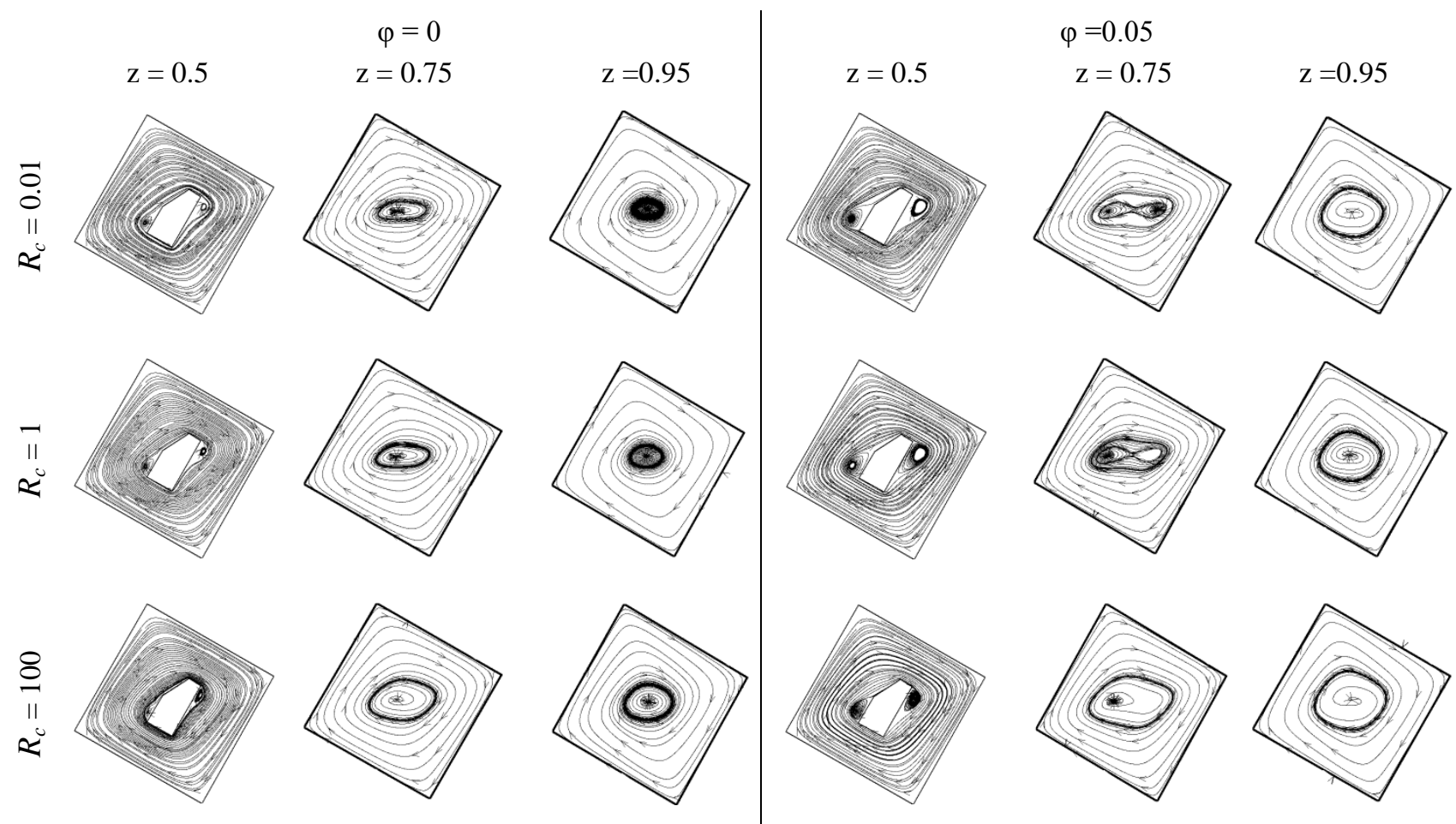

Fig.8. Velocity vector projection at different z-plans for $\gamma=60^{\circ}$ and $\mathrm{Ra}=10^{5}$ 
Fig. 12 shows the average Nusselt number for the case of conductivity ratio equals to 1 for different Rayleigh numbers and volume fraction of CNT-particles. It is observed that for any particular volume fraction when Rayleigh number increases average Nusselt number also increased. Enhancement in fluid flow due to buoyancy leads to increase in average $N u$. Further when particle loading is increased average $N u$ is linearly increased. The maximum variation in Nusselt number is recorded for Rayleigh number equals to $10^{3}$. It is interestingly noticed that for certain angle there is no distinct variation in average $\mathrm{Nu}$.

Fig. 13 shows the effect of $R_{c}$ on average Nusselt number. It is observed that the average Nusselt for any $R_{c}$ value is respond to certain angle significantly and rather response to remaining angles. The curves are nearly in horizontal and a slight deviation occurred after $R_{c}=1$.

Fig. 14 shows the comparison of average Nusselt number in connection with Rayleigh number and inclination angle in the presence of nanofluid and base fluid. The curve is symmetrical with respect to $90^{\circ}$. It is recorded that low average $\mathrm{Nu}$ for $90^{\circ}$. This is due to large number of inactive recirculation present at this angle. For $30^{\circ}$ and $150^{\circ}$ peak values of average $\mathrm{Nu}$ is recorded. The heat transfer enhanced by the position of Ahmed body at these angles. When $R a$ is increased, buoyancy also increased resulting enhanced heat transfer and is reflected in the fig. 14.

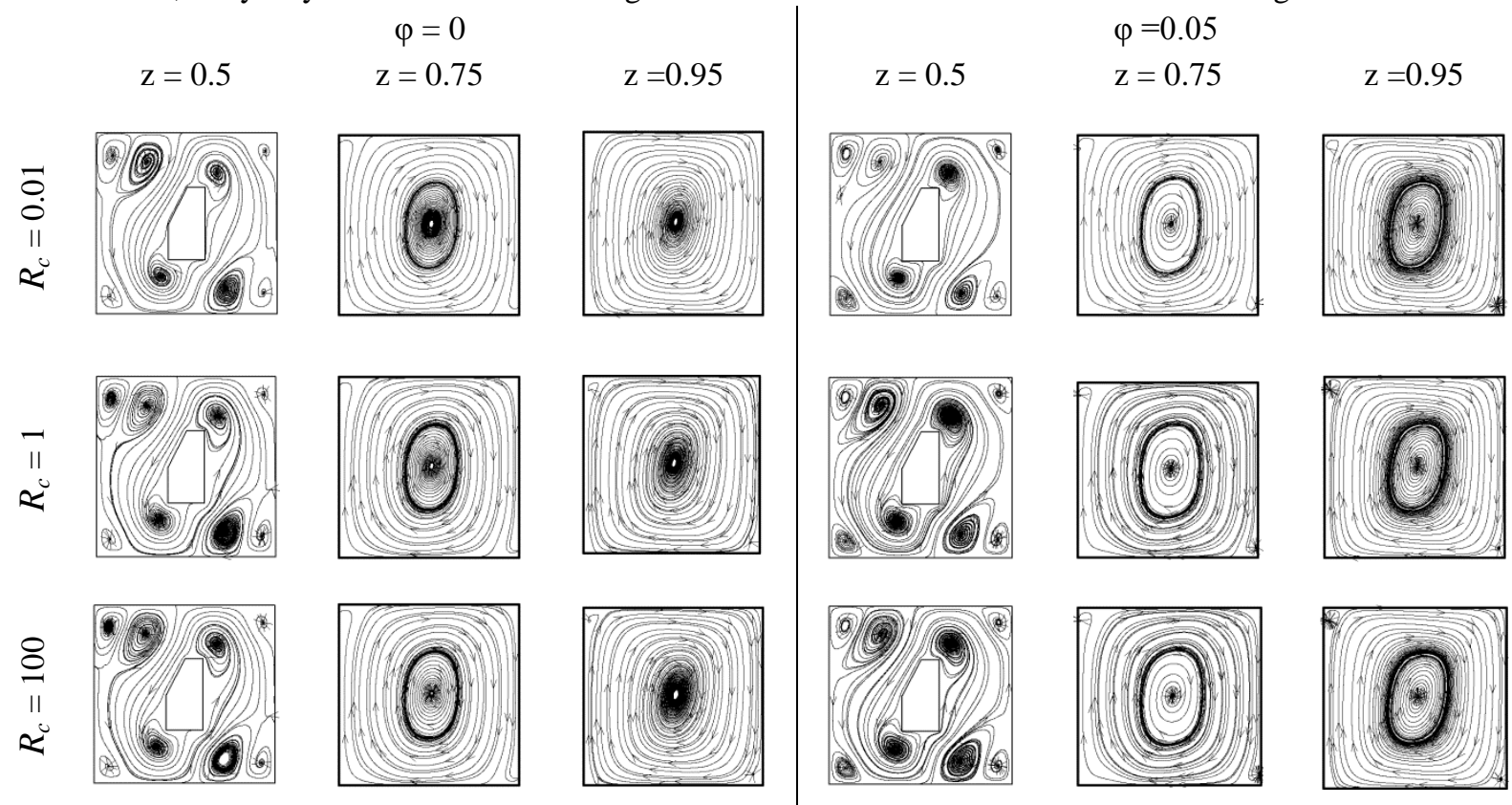

Fig.9. Velocity vector projection at different z-plans for $\gamma=90^{\circ}$ and $R a=10^{5}$

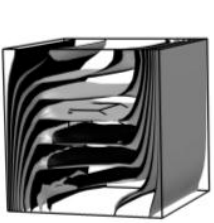

$\gamma=0^{\circ}$

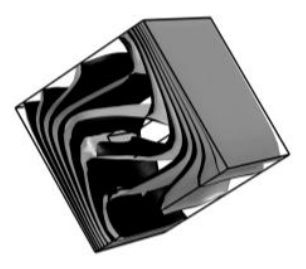

$\gamma=30^{\circ}$

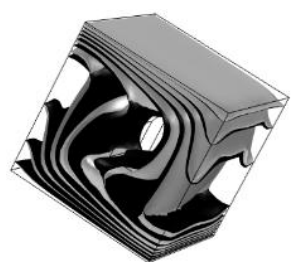

$\gamma=60^{\circ}$

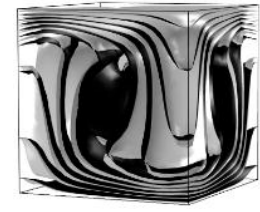

$\gamma=90^{\circ}$

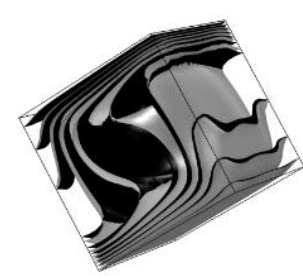

$\gamma=120^{\circ}$

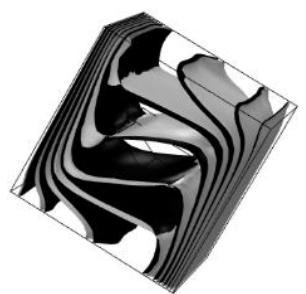

$\gamma=150^{\circ}$

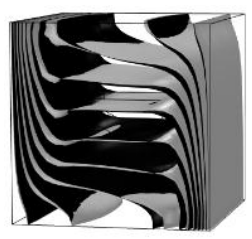

$\gamma=180^{\circ}$

Fig. 10. Iso-surfaces of temperature for $R a=10^{5} ; \varphi=0.05$ (gray) and $\varphi=0$ (black) 

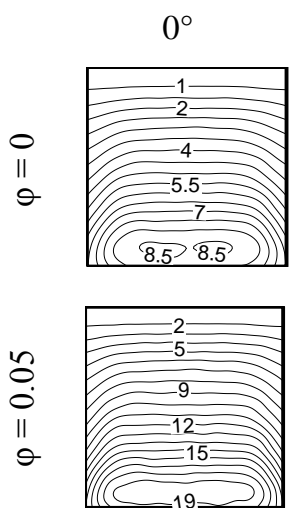

$30^{\circ}$
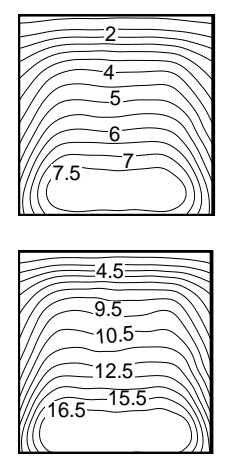

$60^{\circ}$
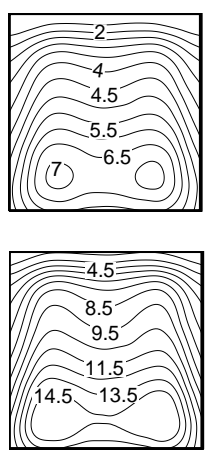

$90^{\circ}$
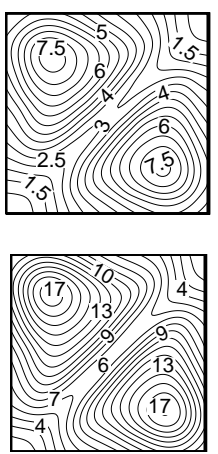

$120^{\circ}$
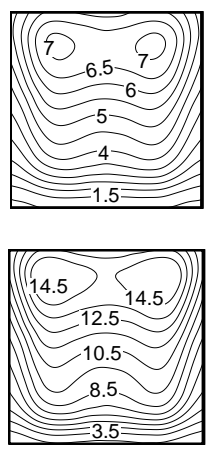

$150^{\circ}$
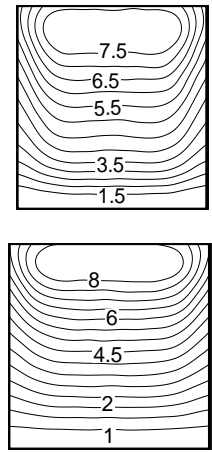

$180^{\circ}$
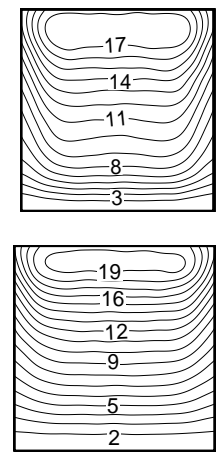

Fig. 11. Local Nusselt number at hot wall for $R a=10^{5} ; R_{c}=1$ for different $\gamma$ and $\varphi$
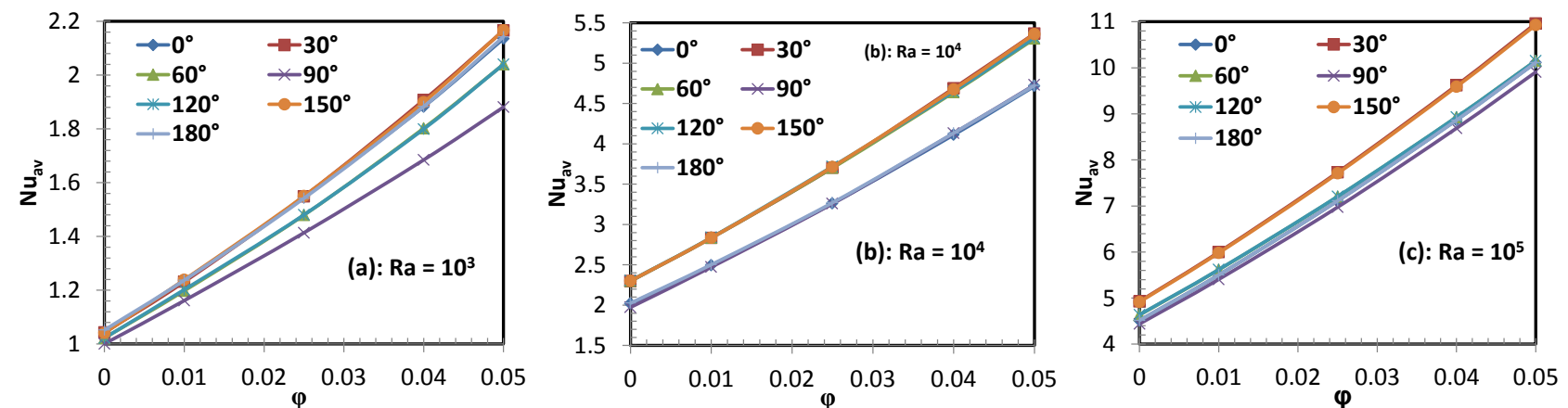

Fig. 12. Average Nusselt number versus $\varphi$; for $R_{c}=1$ and different $\gamma$; (a) $R a=10^{3}$; (b) $R a=10^{4}$; (c) $R a=10^{5}$
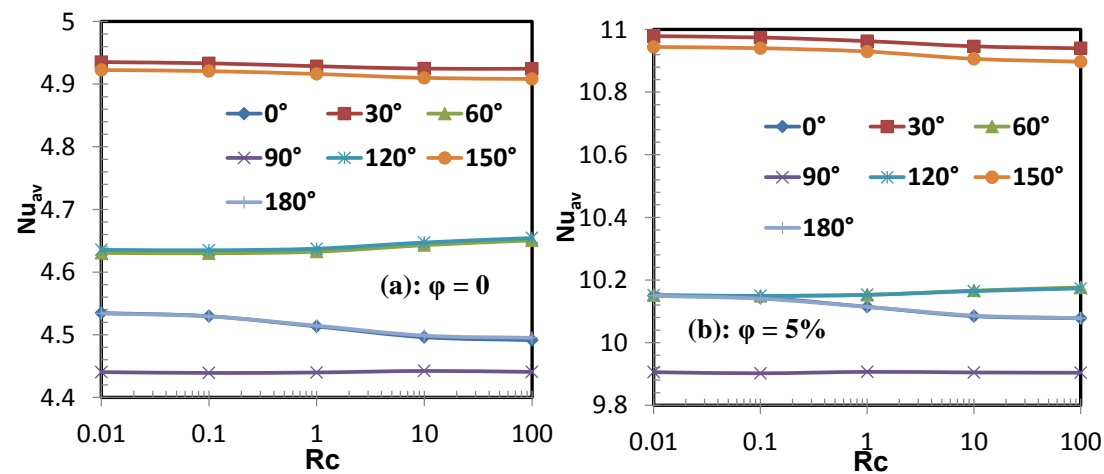

Fig. 13. Average Nusselt number versus $R_{c}$ for $R a=10^{5}$ and different (a) $\varphi=0$; (b): $\varphi=0.05$
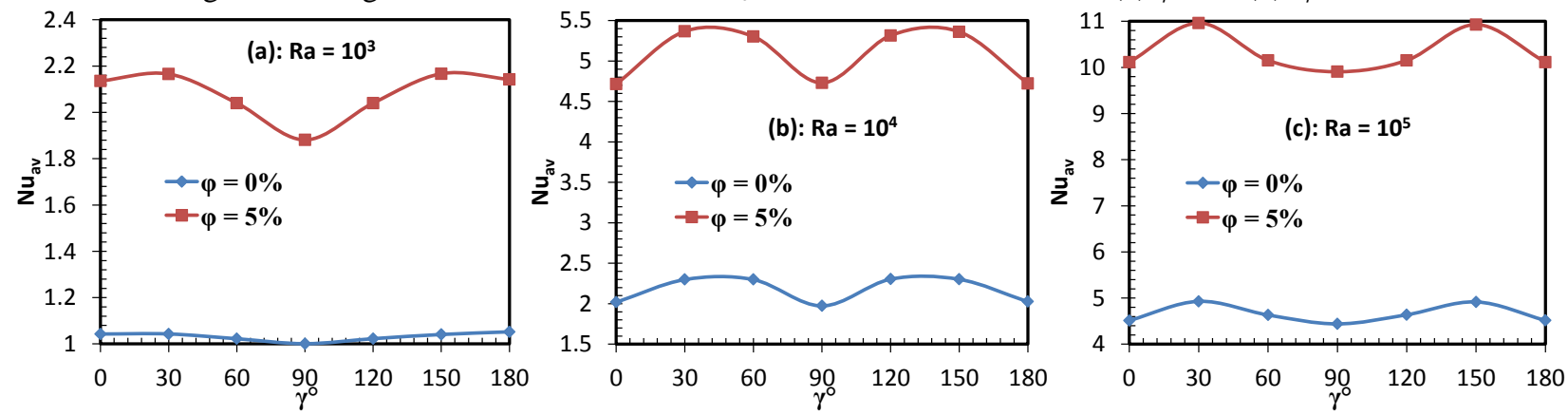

Fig. 14. Average Nusselt number versus $\gamma$ for $R_{c}=1$ and different $\varphi$; (a) $R a=10^{3}$; (b) $R a=10^{4}$; (c) $R a=10^{5}$

\section{Conclusions}

Three dimensional numerical simulations were performed on the cubical cavity containing Ahmed body filled with CNT-water nanofluid. The effect of nanoparticles, angle of incidence of cavity, Rayleigh number and thermal conductivity ratio on heat transfer were investigated. Based on the studies, the following conclusions are obtained:

- The skewness on the backside of the Ahmed body makes the particle trajectories denser around it. 
- The formation of recirculation cells in the velocity vector diagrams are influenced by the Ahmed body at varying angle of incidences of cavity.

- Heat transfer enhances when Rayleigh number increases due to the surge in buoyancy forces.

- Heat transfer intensifies with the addition of CNT-particles for all the considered parameters.

- Maximum average Nusselt number is reported when the angle of inclination is $30^{\circ}$ and $150^{\circ}$, while the minimum intensity is reported at $90^{\circ}$.

- The variation in thermal conductivity ratio has a least effect on convection.

\section{References}

Abu-Nada E., Oztop H.F., Effects of inclination angle on natural convection in enclosures filled with $\mathrm{Cu}$-water nanofluid. International Journal of Heat and Fluid Flow, Vol.30 (2009) pp.669-678.

Banga S., Zunaid M., Ansari N.A., Sharma S., Dungriyal R.S., CFD simulation of flow around external vehicle: Ahmed body. Journal of Mechanical and Civil Engineering, Vol.12, No.4 (2015) pp.87-94.

Corcione M., Cianfrini M., Quintino A., Enhanced natural convection heat transfer of nanofluids in enclosures with two adjacent walls heated and the two opposite walls cooled. International Journal of Heat and Mass Transfer, Vol.88 (2015) pp.902-913.

Das M.K., Reddy K.S.K. Conjugate natural convection heat transfer in an inclined square cavity containing a conducting block. International Journal of Heat and Mass Transfer, Vol.49, No.25, (2006) pp.4987-5000.

De Vahl Davis G., Natural convection of air in a square cavity a benchmark numerical solution. International Journal for Numerical Methods in Fluids, Vol.3, (1983) pp.249-264.

Ding Y., Alias H., Wen D., Richard A. Williams. Heat transfer of aqueous sus- pensions of carbon nanotubes (CNT nanofluids). International Journal of Heat and Mass Transfer, Vol.49 (2006) pp.240-250.

Eslamian M., Ahmed M., El Dosoky M.F., Saghir M.Z.. Effect of thermophoresis on natural convection in a Rayleigh Benard cell filled with a nanofluid. International Journal of Heat and Mass Transfer, Vol.81 (2015) pp.142-156.

Esfandiary M., Mehmandoust B., Karimipour A., Pakravan H.A., Natural convection of $\mathrm{Al}_{2} \mathrm{O}_{3}$ water nanofluid in an inclined enclosure with the effects of slip velocity mechanisms: Brownian motion and thermophoresis phenomenon. International Journal of Thermal Sciences, Vol.105 (2016) pp.137-158.

Fusegi T., Hyun J.M., Kuwahara K., and Farouk B., A numerical study of three-dimensional natural convection in a differentially heated cubical enclosure. International Journal of Heat and Mass Transfer, Vol.34, No.6 (1991), pp.1543-1557.

Ghasemi B., Aminossadati. S.M, Natural convection heat transfer in an inclined enclosure filled with a water-CuO nanofluid. Numerical Heat Transfer, Part A: Applications, Vol.55 (2009) pp.807-823.

Glory J., Bonettid M., Helezen M., Mayne M. Hermite L., Reynaud C., Thermal and electrical conductivities of water-based nanofluids prepared with long multiwalled carbon nanotubes. Journal of Applied Physics, Vol.103(094309) (2008) pp.1-7.

Halelfadl S., Estelle P., Aladag B., Doner N., Mare T., Viscosity of carbon nanotubes water-based nanofluids: Influence of concentration and temperature. Interna- tional Journal of Thermal Sciences, Vol.71 (2013) pp.111-117.

Heris S.Z., Pour M.B., Mahian O., Wongwises S., A comparative experimental study on the natural convection heat transfer of different metal oxide nanopowders suspended in turbine oil inside an inclined cavity, International Journal of Heat and Mass Transfer Vol. 73 (2014) pp. 231-238

Ho C.J., Chen M.W., Li Z.W., Numerical simulation of natural convection of nanofluid in a square enclosure: Effects due to uncertainties of viscosity and thermal conductivity. International Journal of Heat and Mass Transfer, Vol.51 (2008) pp.4506-4516.

Ho C.J., Chen D., Yan W., Mahian O., Buoyancy-driven flow of nanofluids in a cavity considering the Ludwig-Soret effect and sedimentation: Numerical study and experimental validation, International Journal of Heat and Mass Transfer Vol.77 (2014) pp.684-694

Huelsz G., Rechtman R., Heat transfer due to natural convection in an inclined square cavity using the Lattice Boltzmann equation method. International Journal of Thermal Sciences, Vol.65 (2013) pp.111-119.

Jahanshahi M., Hosseinizadeh S.F., Alipanah M., Dehghani A., Vakilinejad G.R., Numerical simulation of free convection based on experimental measured conductivity in a square cavity using water/SiO ${ }_{2}$ nanofluid. International Communications in Heat and Mass Transfer, Vol.37, No.6 (2010) pp.687-694.

Kahveci K., Buoyancy driven heat transfer of nanouids in a tilted enclosure. Journal of Heat Transfer, Vol.132, No.6 
(2010) 062501-1-062501-12.

Kalidasan K., Velkennedy R., Kanna P.R., Buoyancy enhanced natural convection inside the ventilated square enclosure with a partition and an overhanging transverse baffle. International Communications in Heat and Mass Transfer, Vol.56 (2014) pp.121-132.

Kalidasan K., Kanna P.R.. Effective utilization of MWCNT-water nanofluid for the enhancement of laminar natural convection inside the open square enclosure. Journal of the Taiwan Institute of Chemical Engineers, In press, (2016).

Khanafer K., Vafai K., Lightstone M., Buoyancy-driven heat transfer enhancement in a two - dimensional enclosure utilizing nanofluids. International Journal of Heat and Mass Transfer, Vol.46 (2003) pp.3639-3653.

Kolsi L., Oztop H.F., Alghamdi A., Abu-Hamdeh N., Borjini M.N., Ben Aissia H.. A computational work on a three dimensional analysis of natural convection and entropy generation in nanofluid filled enclosures with triangular solid insert at the corners. Journal of Molecular Liquids, Vol.218 (2016a) pp.260-274.

Kolsi L., Kalidasan K., Alghamdi A., Borjini M.N., Kanna P.R., Natural convection and entropy generation in a cubical cavity with twin adiabatic blocks filled by aluminum oxide water nanofluid. Numerical Heat Transfer, Part A: Applications, Vol.70 (2016b) pp.242-259.

Mahian O., Kianifar A., Heris S.Z., Wongwises S., Natural convection of silica nanofluids in square and triangular enclosures: Theoretical and experimental study, International Journal of Heat and Mass Transfer Vol. 99 (2016) pp.792-804

Mahmoodi, M. Sebdani S. M., Natural convection in a square cavity containing a nanofluid and an adiabatic square block at the center. Superlattices and Microstructures, Vol.52 (2012) pp.261-275.

Rahman M.M., Oztop H.F., Steele M., Naim A.G., Al-Salem K., Ibrahim T.A., Unsteady natural convection and statistical analysis in a CNT water filled cavity with non-isothermal heating. International Communications in Heat and Mass Transfer, Vol.64 (2015) pp.50-60.

Rashidi I., Mahian O., Lorenzini G., Biserni C., Wongwises S., Natural convection of $\mathrm{Al}_{2} \mathrm{O}_{3} /$ water nanofluid in a square cavity: Effects of heterogeneous heating, International Journal of Heat and Mass Transfer Vol.74 (2014) pp. 391402

Sarkar S., Ganguly S., Biswas G., Mixed convective heat transfer of nanofluids past a circular cylinder in cross flow in unsteady regime. International Journal of Heat and Mass Transfer, Vol. 55 (2012) pp.4783-4799.

Shen Z.G., Wu S.Y., Xiao L., Wang K., Effect of tilt angle on the stability of free convection heat transfer in an upward-facing cylindrical cavity: Numerical analysis. International Journal of Thermal Sciences, Vol.107 (2016) pp.13-24.

Sheremet M.A., Pop I., Rahman M.M., Three-dimensional natural convection in a porous enclosure filled with a nanofluid using Buongiornos mathematical model. International Journal of Heat and Mass Transfer, Vol.82 (2015) pp.396-405.

Singh D.K., Singh S.N., Combined free convection and surface radiation in tilted open cavity. International Journal of Thermal Sciences, Vol.107 (2016) pp.111-120.

Thacker A., Aubrun S., Leroy A., Devinant P., Experimental characterization of flow unsteadiness in the centerline plane of an Ahmed body rear slant. Experiments in Fluids, Vol.54:1479 (2013).

Wakashima S., Saitoh T.S.. Benchmark solutions for natural convection in a cubic cavity using the high-order time space method. International Journal of Heat and Mass Transfer, Vol.47, No.4 (2004), pp.853-864.

Wang Q.W., Yang J., Zeng M., Wang G., Three-dimensional numerical study of natural convection in an inclined porous cavity with time sinusoidal oscillating boundary conditions. International Journal of Heat and Fluid Flow, Vol.31 (2010) pp.70-82.

Xue Q.Z.. Model for thermal conductivity of carbon nanotube-based composites. Physica B, Vol.368, No.1, (2005) pp.302-307. 